\title{
EDUCACIÓN Y LA PANDEMIA EN AMÉRICA LATINA: LA EXPERIENCIA EN EL PERÚ
}

\author{
A EDUCACÂA E A PANDÊMICA NA AMÉRICA LATINA: A EXPERIÊNCLA NO PERU
}

\author{
Dr. Eduardo José Campechano-Escalona ${ }^{1}$ \\ Universidad Cesar Vallejo -Perú
}

http://dx.doi.org/10.52641/cadcaj.v6i4.548

RESUMEN: La educación, es considerada uno de los sectores más afectados por la pandemia del Covid-19, a nivel global. Según la UNESCO, a mediados de mayo de 2020 más de 1.200 millones de estudiantes de todos los niveles de enseñanza, en todo el mundo, habían dejado de tener clases presenciales en la escuela, de ellos, más de 160 millones eran estudiantes de América Latina y el Caribe, lo que deja en evidencia la gran desigualdad social de la región. Este estudio, tiene como propósito caracterizar la educación en el Perú en tempos de pandemia, como una educación remota de emergencia desequilibrada que afecta a los más vulnerables. Desde un enfoque cualitativo, interpretativo se realiza un estudio de caso complementado con un meta-análisis a partir de una serie de datos. Entre las consideraciones finales que arrojó el estudio es que a pesar de tener una de las economías más fuertes de la región, validado por organismos multilaterales como BANCO MUNDIAL, BID y la CEPAL, no se ha realizado una inversión en educación para poder implementar acciones remediales efectivas frente a la pandemia del Covid-19.

Palabras Clave: Pandemia. Educación Precaria Brecha Digital. Datos Estadísticos.

RESUMO: A educação é considerada um dos setores mais afetados pela pandemia Covid-19 em nível global. Segundo a UNESCO, em meados de maio de 2020 mais de 1.200 milhões de alunos de todos os níveis de ensino, em todo o mundo, haviam deixado de ter aulas presenciais na escola, deles, mais de 160 milhões eram alunos da América Latina e do Caribe, o que revela a grande desigualdade social na região. O objetivo deste estudo é caracterizar a educação no Peru em tempos de pandemia, como uma educação emergencial à distância desequilibrada que atinge os mais vulneráveis. A partir de uma abordagem qualitativa e interpretativa, é realizado um estudo de caso, complementado com uma meta-análise a partir de uma série de dados. Entre as considerações finais que o estudo revelou é que apesar de ter uma das economias mais fortes da região, validada por organismos multilaterais como o BANCO MUNDIAL, BID e CEPAL, nenhum investimento foi feito em educação para poder implementar ações corretivas eficazes. contra a pandemia Covid-19.

Palavras-chave: Pandemia. Gap digital da educação precária. Dados estatísticos.

\section{INTRODUCCIÓN}

Los cambios que han surgido en la estructura política, económica y social de nuestra realidad latinoamericana demandan el accionar de los distintos actores que conviven para que

\footnotetext{
${ }^{1}$ Dr. Ciencias de la Educación. Master en Lingüística. Profesor de Lengua. Catedrático de Metodología de la Investigación. Adscrito al Vicerrectorado de Investigación de la Universidad César Vallejo. Línea de Investigación. Educación para la Sostenibilidad. E-mail: ecampechano@ucv.edu.pe. https://orcid.org/0000-0002-6152-7071
} 
asuman con mayor compromiso su condición de líderes ante los escenarios que surgen en esta nueva dinámica social. De ahí que varios organismos multilaterales como el BID (Banco Interamericano de Desarrollo), Banco Mundial, la CEPAL y el PNUD (Programa de las Naciones Unidas para el Desarrollo), sostienen que el lento crecimiento económico mundial, las desigualdades sociales y la degradación ambiental que son característicos de nuestra realidad actual presentan desafíos sin precedentes para la comunidad internacional y en especial para la comunidad latinoamericana.

Cerrando la segunda década del siglo XXI, hemos observado cómo en el contexto latinoamericano, se han dado lugar a varias manifestaciones públicas exigiendo cambios sociales, un proceso de transformación en el paradigma de desarrollo dominante hacia uno que nos lleve por la vía del desarrollo sostenible, inclusivo y con visión de largo plazo.

En América Latina y el Caribe, considerada la región más desigual del mundo, tal desigualdad se presenta como una limitación para alcanzar el potencial de la región, rica en recursos naturales, pero sin capacidad para su transformación y aprovechamiento. A esta realidad hay que sumarle la escasa productividad y una infraestructura deficiente, segregación y rezagos en la calidad de los servicios de educación y salud, persistentes brechas de género y desigualdades territoriales, además de un impacto desproporcionado del cambio climático en los eslabones más pobres de la sociedad. Durante la pandemia del Covid-19, esas deficiencias se profundizaron, mostrando el abandono por parte del estado de una de sus obligaciones y funciones principales la educación

Perú, según el Instituto Nacional de Estadística e Informática (INEI), en lo que va del presente siglo, su economía ha presentado periodos importantes de crecimiento económico, influenciado por un entorno externo favorable, distinguiéndose como uno de los países de mayor dinamismo en América Latina. Es así que, en los últimos 27 años (1993 y 2019) la economía peruana logró un crecimiento promedio anual de 4,8\%; en los últimos diez años (2010-2019) la economía creció a una tasa interanual de 4,5\% y en los últimos cinco años (2015-2019) se expandió a un promedio anual de $3,2 \%$.

Lamentablemente, todo este crecimiento no fue utilizado por el estado para invertir en educación. Datos de organismos como IPE (Instituto Peruano de Economía) y Sutep (Sindicato de Trabajadores educacionales del Perú), sostienen, por el contrario que el gasto público en educación, de Perú disminuyó 52 millones en 2018, es decir un 0,62\%, hasta 8.375,1 millones de dólares, con lo que representó el 17,13\% del gasto público total. Esta cifra supone que el gasto público en educación en 2018 alcanzó el 3,72\% del PIB, una caída de 0,22 puntos respecto a 2017, cuando el gasto fue el 3,94\% del PIB. 
En 2018, Perú se mantuvo en la misma posición en el ranking de países por importe invertido en educación, en el que ocupa el puesto 45. En cuanto a su proporción respecto al PIB, Perú ha descendido hasta la posición 122, de 191 países. En referencia al porcentaje que supone la inversión en educación respecto al presupuesto gubernamental (gasto público), Perú se encuentra en el puesto 54 .

El Banco Mundial, publicó cifras donde explica que el país se ha visto gravemente afectado por la pandemia del COVID-19. Una cuarentena estricta y prolongada que llevó a un descenso del PBI de $11.1 \%$ en el 2020. El empleo cayó en promedio 20\% entre abril y diciembre. En este contexto, se paralizaron las clases presenciales en todos los niveles educativos para evitar el contagio. El gobierno desarrolló un programa educativo denominado “Aprendo en Casa" para tratar de llevar la educación inicial, primaria y secundaria de manera remota a las poblaciones más vulnerables, sin embargo, se encontró con la dificultad que no todos podían acceder a los contenidos, ya que, en varias zonas urbanas y rurales, no existía la infraestructura para implementar una educación a distancia. Datos que se recogen del sitio web del Sutep, muestran datos que evidencian la anterior afirmación: El 79\% de los locales educativos no tiene acceso a Internet, el $55 \%$ de los docentes no poseen habilidades para usar tecnologías digitales. El 90\% de los centros educativos es de primaria y el 73\% de secundaria. El 64\% de los niños están expuestos a riesgos cibernéticos. También indican que 230 mil estudiantes de primaria y secundaria han salido del sistema educativo, otros 200 mil matriculados no están asistiendo a clase, aunado a que más de 65000 jóvenes de educación superior dejaron de estudiar, 170.000 están en riesgo de perder su ciclo académico por falta de una infraestructura digital

En el Perú existen 8 alumnos por computadora en primaria, y 6 en secundaria. La brecha tecnológica en el país es grande. Esta alarmante brecha digital a nivel nacional ratifica la situación de abandono de la educación peruana por parte del estado. El último informe de competitividad desarrollado por el Foro Económico Mundial la sitúa en el puesto 127 en calidad del sistema educativo de 137 países, uno de los factores de peso que tiene en cuenta este ranking es la adopción de los países a las TICs (Tecnologías de información y comunicación).

Desde esta perspectiva, es muy compleja la situación por la que atraviesa Perú ya que con estos datos se evidencia que está muy lejos de que el estado pueda cumplir con la meta de la agenda 2030 y los Objetivos del Desarrollo Sostenible, considerado el mayor de los acuerdos y compromiso que asumen los países para planificar acciones por un mundo más equitativo y con mejores condiciones de cara para el 2030. Este documento, aprobado en septiembre del 2015, es asumido como una guía para que los diversos actores sociales se comprometan a un futuro mejor. 
Fomenta el espíritu de la solidaridad y colaboración para satisfacer las necesidades de los más pobres.

Dentro de la Agenda se estructuran los diecisiete (17) Objetivos de Desarrollo Sostenible (ODS), de los cuales se desprenden 169 metas. Cada uno de los 17 objetivos presenta una serie de indicadores desde la dimensión social, ambiental y económica. Están agrupados en cinco P: personas, planeta, paz, prosperidad y pacto. Todos articulados para lograr el mayor nivel de solidaridad para los grupos humanos más vulnerables.

La Agenda y sus ODS, están inspirados en la Declaración Universal de los derechos Humanos, la Declaración del Milenio, la Cumbre Mundial sobre el Desarrollo Sostenible y otros instrumentos que le precedieron como la Declaración de Río sobre el Medio Ambiente, Cumbre Mundial de la Tierra, la Plataforma de Acción de Beijing, entre otros.

Los 17 ODS y las 169 metas integradas abordan temas como la erradicación de la pobreza, la salud, educación, seguridad alimentaria, igualdad de género, infraestructura, vida marina, ciudades sostenibles y una gama de temáticas que apuntan a la consolidación de las bases de una sociedad más inclusiva y pacífica. Cada uno de los objetivos tienen en cuenta las características, realidades, capacidades y niveles de desarrollo de cada país, no obstante, están formulados para lograr movilizar esfuerzos y recursos para su implementación y logro.

El siguiente cuadro presenta los ODS:

\begin{tabular}{|c|c|c|c|}
\hline 1. Fin de la Pobreza & 2. Erradicar el Hambre & $\begin{array}{l}\text { 3. Garantizar la salud } \\
\text { y Bienestar }\end{array}$ & $\begin{array}{l}\text { 4. Garantizar una } \\
\text { educación de calidad }\end{array}$ \\
\hline $\begin{array}{l}\text { 5. Lograr la igualdad de } \\
\text { género }\end{array}$ & $\begin{array}{l}\text { 6. Garantizar agua } \\
\text { limpia y saneamiento }\end{array}$ & $\begin{array}{l}\text { 7. Garantizar la } \\
\text { energía asequible y } \\
\text { no contaminante }\end{array}$ & $\begin{array}{l}\text { 8. Promover el } \\
\text { trabajo decente y } \\
\text { crecimiento } \\
\text { económico }\end{array}$ \\
\hline $\begin{array}{lr}9 . \quad \text { Promover } & \text { la } \\
\text { industrialización, } & \text { la } \\
\text { innovación } & \text { e } \\
\text { infraestructura } & \end{array}$ & $\begin{array}{l}\text { 10. Reducir las } \\
\text { desigualdades }\end{array}$ & $\begin{array}{l}\text { 11. Lograr ciudades y } \\
\text { comunidades } \\
\text { sostenibles }\end{array}$ & $\begin{array}{ll}\text { 12. Garantizar la } \\
\text { producción y el } \\
\text { consumo } \\
\text { responsable }\end{array}$ \\
\hline $\begin{array}{l}\text { 13. Adoptar acciones por el } \\
\text { clima }\end{array}$ & $\begin{array}{l}\text { 14. Conservar la vida } \\
\text { submarina }\end{array}$ & $\begin{array}{l}\text { 15. Proteger y } \\
\text { promover la vida de } \\
\text { ecosistemas } \\
\text { terrestres }\end{array}$ & $\begin{array}{l}\text { 16. Promover la paz, } \\
\text { justicia } \\
\text { instituciones sólidas }\end{array}$ \\
\hline
\end{tabular}


Pensar en acciones orientadas a construir una sociedad más justa y equitativa parece una utopía, si revisamos los datos que platea el informe de la CEPAL (2017)” ... sobre el panorama social de América Latina, la pobreza y pobreza extrema han ido aumentando en la región desde el año 2014. Hasta esa fecha, la pobreza había disminuido de forma progresiva desde 2002. Sin embargo, esa tendencia ha cambiado en los últimos años..."

Figura 1 Panorama Social de América Latina

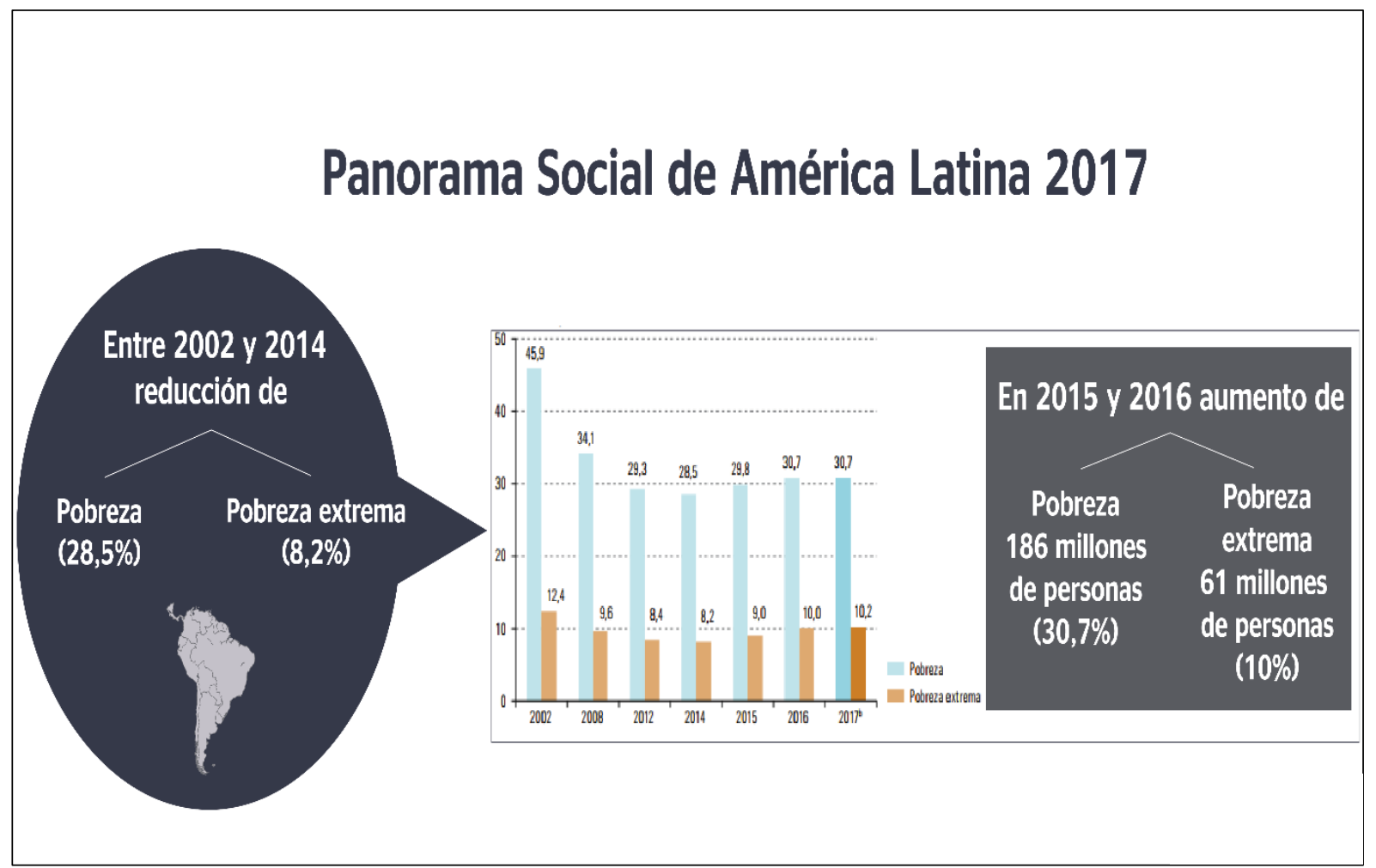

Fuente: CEPAL (2017)

En su Informe COVID-19, la CEPAL-UNESCO (2020), se ha identificado grandes brechas en los resultados educativos, que se relacionan con una desigual distribución de los docentes, en general, y de los docentes mejor calificados, en particular, en desmedro de países y regiones con menores ingresos y de zonas rurales, las que suelen concentrar además a población indígena y migrante (UNESCO, 2016a; Messina y García, 2020). En el ámbito educativo, gran parte de las medidas que los países de la región han adoptado ante la crisis se relacionan con la suspensión de las clases presenciales en todos los niveles, lo que ha dado origen a tres campos de acción principales: el despliegue de modalidades de aprendizaje a distancia, mediante la utilización de una diversidad de formatos y plataformas (con o sin uso de tecnología); el apoyo y la movilización del personal y las comunidades educativas, y la atención a la salud y el bienestar integral de las y los 
estudiantes. A pesar de esto, la mayoría de los países de la región evidencian una brecha digital y poco acceso a una infraestructura digital, tal y como se muestra en el siguiente gráfico:
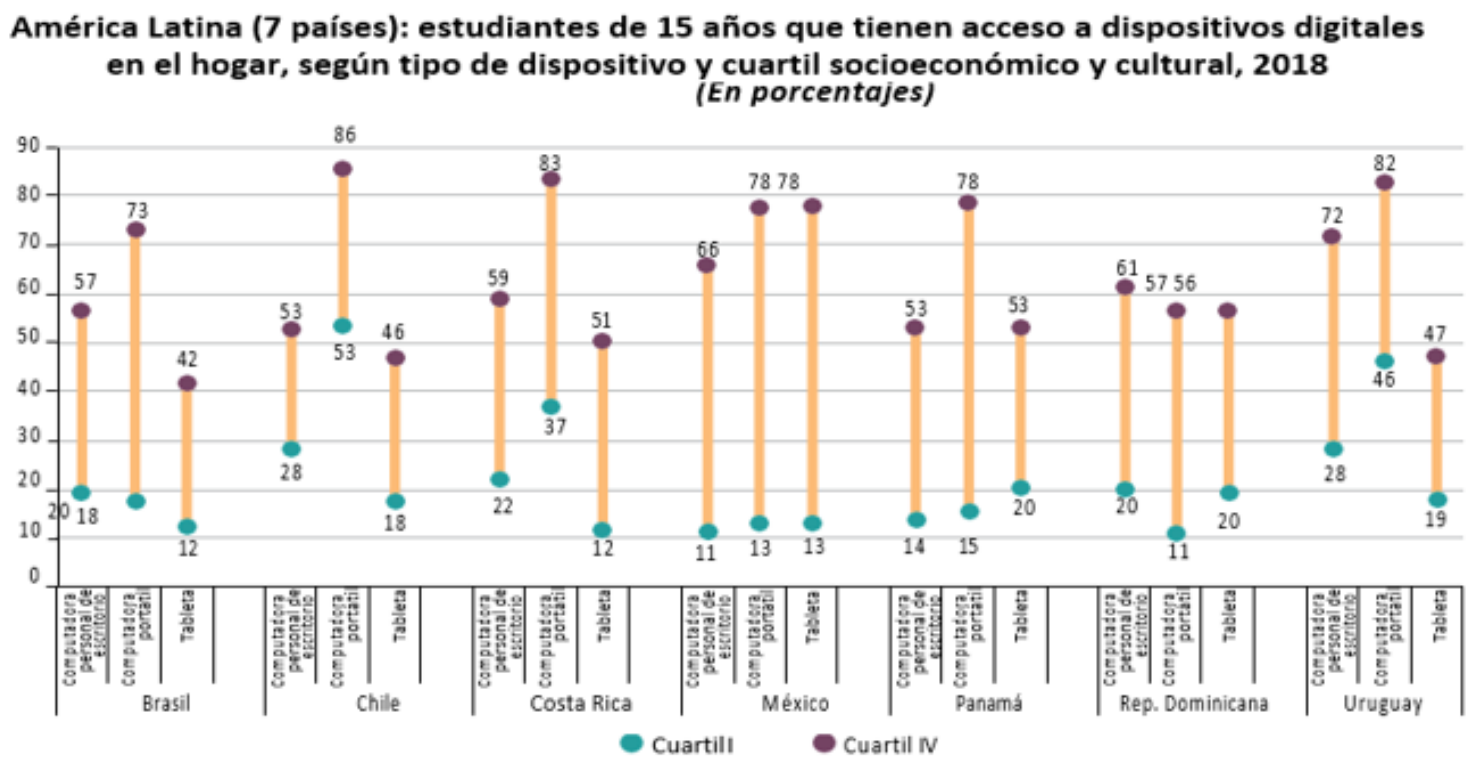

Fuente: Comisión Económica para América Latina y el Caribe (CEPAL), sobre la base de datos de Organización de Cooperación y Desarrollo Económicos (OCDE), Programa para la Evaluación Internacional de Estudiantes (PISA), 2018.

Partiendo de las ideas expuestas y considerando la observación participante del autor, el objetivo de este estudio es caracterizar la educación en Perú en tiempos de pandemia como una educación remota de emergencia desequilibrada, a partir de un metanálisis de datos estadísticos y la interpretación de la realidad social. Se trata de una investigación exploratoria, descriptiva y explicativa a través del estudio de caso.

\section{DESARROLLO}

Este estudio de caso, se apoya en la recopilación de datos de diversas fuentes para describir el estado social en que se encuentra Perú y en especial la educación en medio de la Pandemia del Covid-19.

Una de esas fuentes es el Celag (2020), el cual hace referencia a la encuesta Pulso Perú (Datum), reveló que entre febrero y abril los ingresos de los trabajadores peruanos se redujeron en un 48\%, pues se pasó que en promedio ganen S/ 1.733 a S/ 909. La incidencia de esta situación fue aún mayor en los niveles socio-económicos bajos (D/E), donde se encuentran principalmente los trabajadores informales, ya que la reducción fue del 58\% al pasar de percibir en promedio S/ 1.017 en febrero, mes previo al confinamiento obligatorio, a sólo S/ 425 en el mes de abril. 
Previamente, una encuesta de Ipsos había develado que el 42\% de los peruanos se quedó sin trabajo o sin percibir ingresos por lo que era su trabajo.

Esto trajo como consecuencia que el nivel de desigualdad social aumentara y los más vulnerables de la población sean los más afectados, tal y como se muestra en las siguientes imágenes:

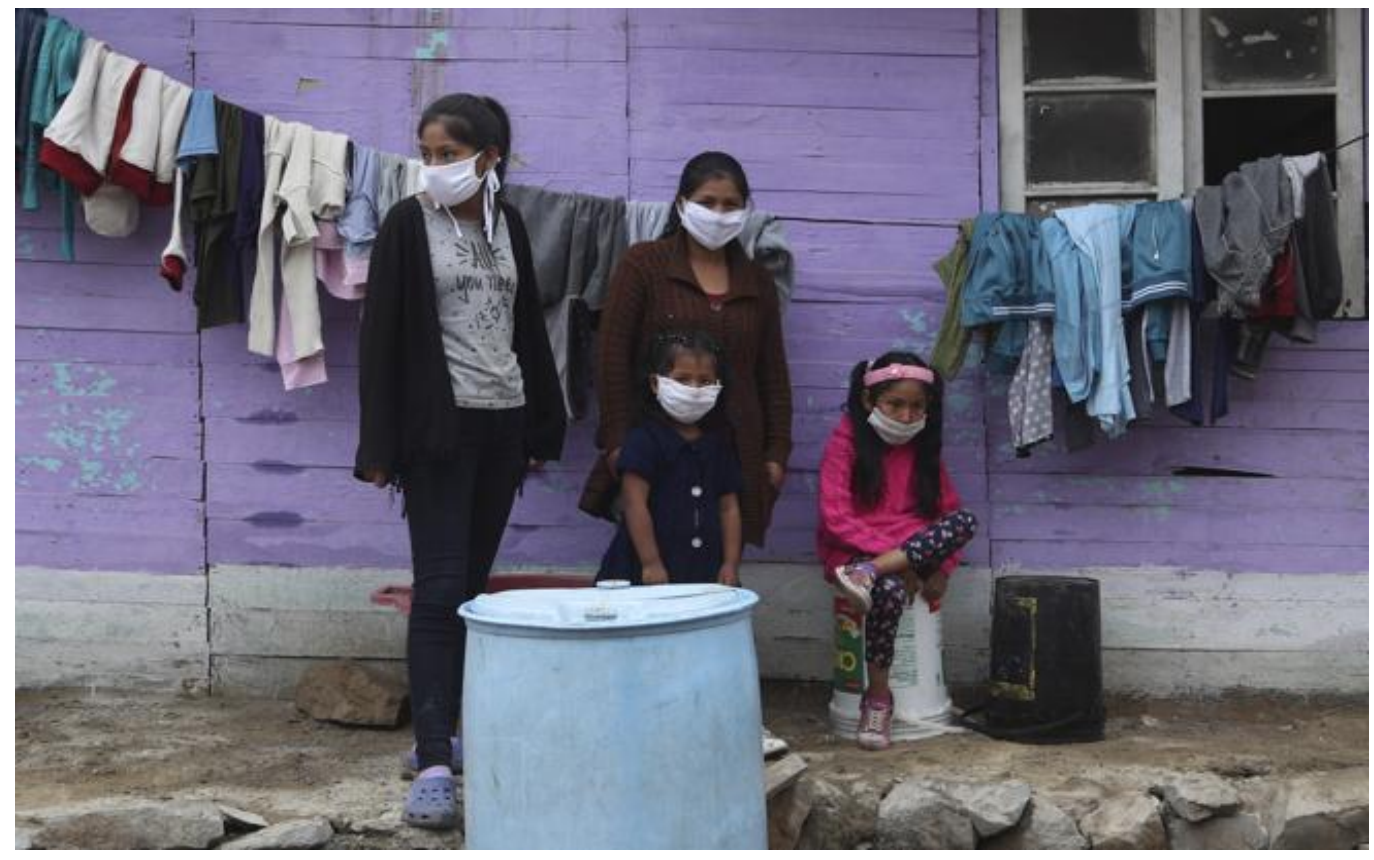

Imagen 1. Autor: Mejía, M.

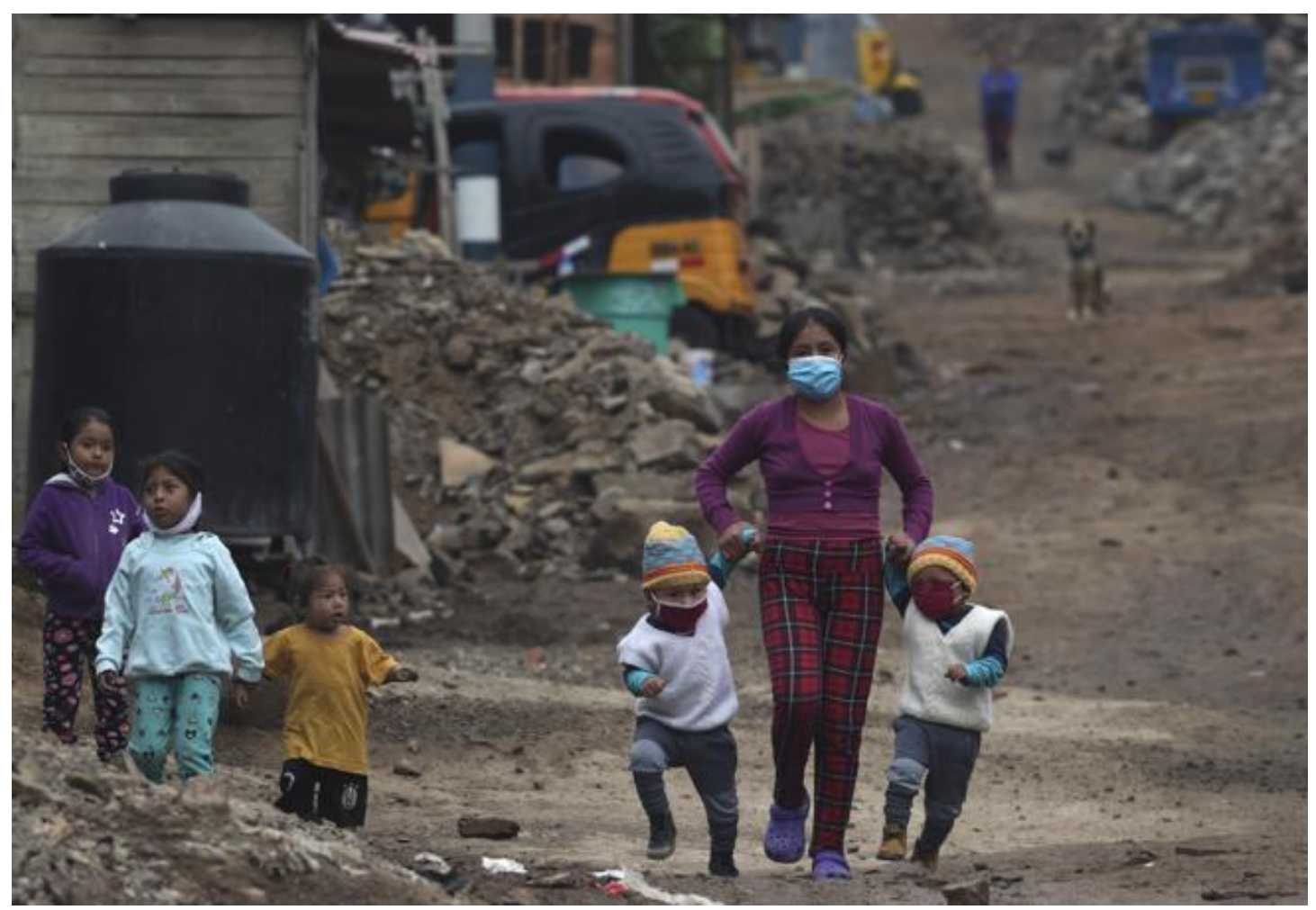

Imagen 2. Autor: Mejía, M.

Cadernos Cajuína, v. 6, n. 4, 2021, p. 218-228. 
Dentro de este escenario, el sector educativo, ha sido el más golpeado y se evidencia como frágil y precario, tal y como lo reseña el periodista Mujica Rojas (2020) en el portal web, la Mula: “...en el sector de la educación pública en países como Perú, los colegios -menos aún los públicosno tienen sino en una proporción limitada plataformas para dar enseñanza a distancia a los alumnos o si las hay es solo para un determinado número de materias y no siempre en condiciones técnicas impecables. Por otro lado, por sus limitados ingresos las familias de pocos ingresos o no poseen laptops o computadoras en sus casas, si las hay, no todos tienen un sistema de wifi que les permita acceder a las redes de internet. En todos los lugares, por último, la llegada del internet incluso la satelital, es muy deficiente y hemos visto penosas situaciones en que los niños en muchos lugares de la Sierra del Perú, tienen que caminar a veces horas para llegar a algún lugar donde puedan captar la señal wifi en forma fluida e impecable para poder acceder a alguna forma de enseñanza a distancia. En otros casos han tenido por así decirlo de colgarse del WhatsApp de sus padres para seguir una clase..."

Esta visión del autor, viene a corroborar los que los datos muestran. Perú, como todos los países latinoamericanos, ha implementado medidas improvisadas para hacer frente a este estado de emergencia. En el siguiente gráfico, se muestran las medidas asumidas por los países para hacerle frente a esta emergencia sanitaria:

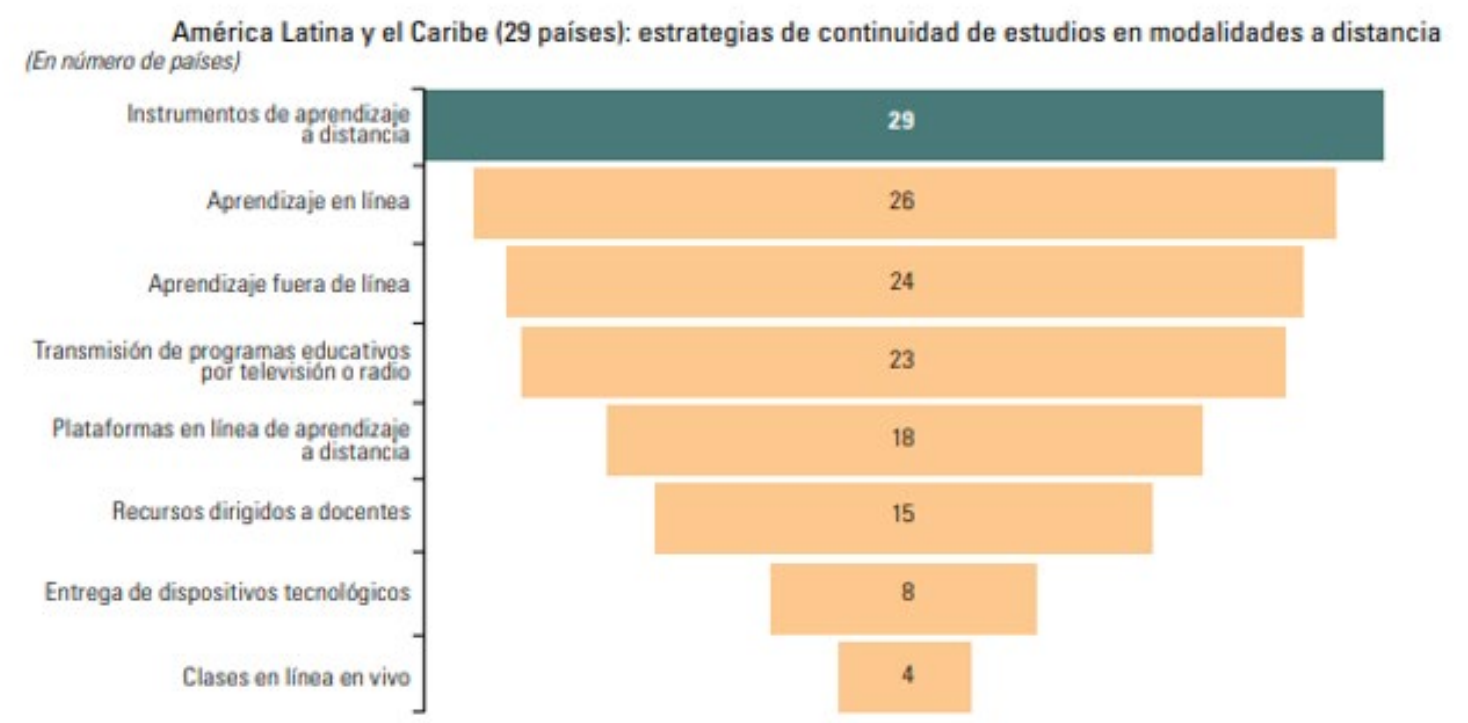

Fuente:Comisión Económica para America Latina y el Caribe (CEPAL), sobre la base de Sistema de Información de Tendencias Educativas en América Latina (SITEAL). "Sistematización de respuestas de los sistemas educativos de América Latina a la crisis de la COVD-19", 2020 [en linea] https:-/www.siteal_iiep.unesco.org/respuestas_educativas_covid_19.

Frente a estas medidas, hay que resaltar el nivel de deserción que se tiene en el país, en estos tiempos de pandemia. Según datos del Ministerio de Educación, reseñado por el portal de noticias 
RPP, “...la tasa de la deserción había pasado de $2.5 \%$ en el 2018 a 1.3\% en el 2019 en primaria. En secundaria, se había logrado bajar de $4.1 \%$ a 3.5\%. Sin embargo, para el 2020, hasta el cierre de la matrícula extraordinaria que hizo Minedu en julio, la deserción pasó de 1.3\% a 3.5\% en primaria y en secundaria, de 3.5\% a 4\%. Según el Ministerio de Educación, 130 mil niños y niñas de primaria no se han matriculado este año. En secundaria, el número llega a 100 mil. Es así que 230 mil estudiantes han salido este año del sistema educativo. El ministerio también advierte que más de 200 mil estudiantes de secundaria no están accediendo al servicio educativo a distancia, pese a estar matriculados..."

Frente a este escenario, pensar en un proyecto pedagógico interdisciplinario que asegure el logro del Objetivo 4 de la Agenda 2030 de la ONU, es muy complicado ya que los actores sociales involucrados, estudiantes, docentes, padres y representantes, no tienen las condiciones ni las competencias para desarrollarlo, por otra parte, no existe una política pública desde el estado que asegure la calidad educativa y la continuidad del servicio educativo, por lo tanto, el tan anhelado desarrollo sostenible del país, está lejos de alcanzarse.

\section{CONSIDERACIONES FINALES}

El Panorama social del Perú, siempre se ha caracterizado por los altos niveles de informalidad, lo cual se ve reflejada en todos los sectores. La educación no escapa de esto. Según datos de https la ONG Oxfam (2020)” ... Más del 70 \% de la población peruana trabaja en la informalidad, sin contratos o protección, y sin seguridad laboral o licencias por enfermedad. Desde el comienzo del confinamiento el 16 de marzo, 2,3 millones de personas que viven en Lima, la capital de Perú, han perdido sus trabajos y la capacidad de alimentar a sus familias. Ya son 200000 quienes han huido a pie de las ciudades a sus pueblos de origen en el campo, algunos llevándose el virus con ellos..." A partir de estas cifras se puede inferir que la gran mayoría de los niños y jóvenes sufrieron las consecuencias, puesto que la prioridad es la alimentación y la supervivencia.

El estado peruano, no ha tenido la capacidad logística y operativa para poder implementar planes de contingencia en el sector educación. El gran avance y crecimiento económico que reflejaban las cifras de organismo internacionales como, la CEPAL, CAF, UNESCO y BID, no están acorde con los altos niveles de abandono de la infraestructura educativa. La articulación que debe existir entre estado, empresa privada y sociedad civil como factor clave para la implementación de la Agenda 2030 para el Desarrollo Sostenible, no se presenta en este escenario. Lejos se está de asumir, la agenda, como instrumento de planificación para el logro de una 
educación de calidad, tal y como lo expresa el ODS 4, esencial para superar las inequidades y lograr un mayor nivel de inclusión social.

Las cifras que se han mostrado en este estudio, sirven para hacer una prospectiva de cómo avanza la educación peruana, hacia donde va. Se podría decir, que su futuro es incierto ya que la pandemia del Covid-19, ha evidenciado que en el Perú existen grandes brechas sociales que se refleja en una mayor brecha digital, la cual ha evidenciado la otra cara del progreso, la falsa idea de desarrollo económico que hasta la fecha se reflejaban en estadísticas macroeconómicas que sugerían, según la OCDE, que el país, estaba por los caminos de una economía emergente y una clara superación de la pobreza social e institucional.

\section{REFERÊNCIAS}

BANCO MUNDIAL (2020) Perú: panorama general. Consultado el 5 de abril de 2021: https://www.bancomundial.org/es/country/peru/overview

BARRENECHEA ARANGO, M (2020, 21 septiembre) El peligro de la deserción escolar durante la pandemia: ¿Cómo evitar una tragedia educativa en el Perú? Consultado el 10 de Abril de 2021: https://rpp.pe/politica/estado/el-peligro-de-la-desercion-escolar-durante-lapandemia-como-evitar-una-tragedia-educativa-en-el-peru-noticia-1293377

CEPAL (2020) La educación en tiempos de la pandemia de COVID-19.: https://www.cepal.org/es/publicaciones/45904-la-educacion-tiempos-la-pandemia-covid-19.

CEPAL (2019) Agenda 2030 y los Objetivos de Desarrollo Sostenible Una oportunidad para América Latina y el Caribe: https://www.cepal.org/es/publicaciones/40155-la-agenda-2030objetivos-desarrollo-sostenible-oportunidad-america-latina-caribe

GUERRA VÁSQUEZ, R (2020, 21 de abril) E1 42\% de peruanos están sin trabajo o ya no perciben ingresos a causa de la cuarentena por el coronavirus. Consultado el 10 de abril de 2021:https://elcomercio.pe/economia/peru/covid-19-el-42-de-peruanos-estan-sin-trabajo-o-yano-perciben-ingresos-a-causa-de-la-cuarentena-por-el-coronavirus-desempleo-informales-trabajonoticia/?ref $=$ ecr

IESALC-UNESCO (2020) La pandemia Covid-19 en Perú: una oportunidad para enseñar y aprender de otra manera en la universidad: https://www.iesalc.unesco.org/2020/10/06/lapandemia-covid-19-en-peru-una-oportunidad-para-ensenar-y-aprender-de-otra-manera-en-launiversidad/

INSTITUTO PERUANO DE ECONOMÍA (2020) Educación: ¿por qué es inviable establecer un monto mínimo de gasto público? Consultado el 10 de abril de 2021: https://www.ipe.org.pe/portal/educacion-por-que-es-inviable-establecer-un-monto-minimo-degasto-publico/ 
MEjÍA, M(2020, 06 de junio) Carmen Ayasta lleva a su hijo mientras esperan un desayuno en un comedor de beneficencia en el barrio de chabolas de Flor de Amancaes en Lima, Perú. Consultado el 6 de abril 2021:

https://www.lavanguardia.com/20200609/481672450669/brecha-educacion-pobreza-ninosperu-escuela-confinamiento-covid-19-aprendo-en-casa..

MEJÍA, M(2020, 06 de junio) Una niña camina con sus hermanos en el barrio marginal de Puente Piedra en las afueras de Lima.. Consultado el 6 de abril 2021:

https://www.lavanguardia.com/20200609/481672450669/brecha-educacion-pobreza-ninosperu-escuela-confinamiento-covid-19-aprendo-en-casa..

MUJICA ROJAS, H (2020, 17 de julio) La pandemia y la educación escolar. Consultado el: 4 de abril de 2021: https://herbertmujicarojas.lamula.pe/2020/07/17/la-pandemia-y-la-educacionescolar/herbertmujicarojas/

OECD(2018) El Programa para la Evaluación Internacional de Estudiantes. https://www.oecd.org/pisa/39730818.pdf

PRIALÉ, J (2020,06 de mayo) Ingreso promedio de trabajadores cayó $48 \%$ entre febrero y abril. Consultado el 9 de abril de 2021: https:/gestion.pe/economia/datum-ingreso-promediode-trabajadores-cayo-48-entre-febrero-y-abril-noticia/

SINDICATO UNITARIO DE TRABAJADORES EN LA EDUCACIÓN DEL PERÚ (2020) Brecha digital en el Perú impide aprovechar las TICs. Consultado el 4 de abril de 2021: https://sutep.org/articulos/brecha-digital-en-el-peru-impide-aprovechar-las-tics/

SITEAL.IIEP.UNESCO (2020) Sistematización de respuestas de los sistemas educativos de América Latina a la crisis de la Covid-19. Consultado el 11 de abril de 2021. https://siteal.iiep.unesco.org/respuestas educativas covid 19

THÉRIAULT, A (2020, 27 de julio) Aumentan los milmillonarios de América Latina a medida que la región más desigual del mundo se hunde bajo el impacto del coronavirus. Consultado el 10 de abril de 2021: https://www.oxfam.org/es/notas-prensa/aumentan-los-milmillonarios-de-america-latina-medida-que-la-region-mas-desigual

ONU (2015). Transformar nuestro mundo: la Agenda 2030 para el Desarrollo Sostenible. Asamblea General de las Naciones Unidas. 18 de septiembre de 2015: http://www.un.org/ga/search/view doc.asp?symbol=A/70/L.1\&Lang=S 